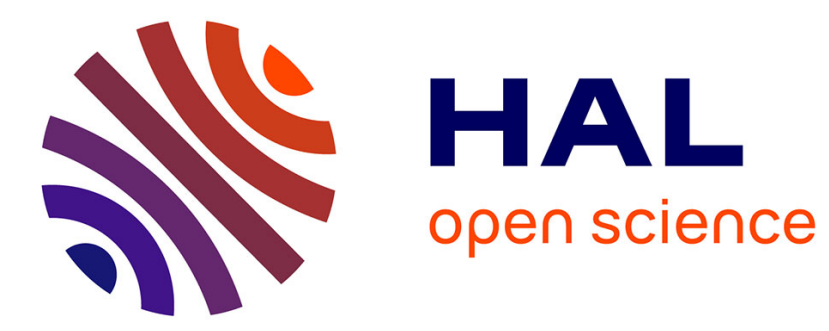

\title{
Thermomechanical processing and mechanical characteristics of particle-strengthened iron aluminide-based alloys
}

\author{
E. Batawi, J. Phillips, Jochen Peters, G. Eggeler
}

\section{- To cite this version:}

E. Batawi, J. Phillips, Jochen Peters, G. Eggeler. Thermomechanical processing and mechanical characteristics of particle-strengthened iron aluminide-based alloys. Journal de Physique IV Proceedings, 1993, 03 (C7), pp.C7-461-C7-464. 10.1051/jp4:1993773 . jpa-00252193

\section{HAL Id: jpa-00252193 https://hal.science/jpa-00252193}

Submitted on 1 Jan 1993

HAL is a multi-disciplinary open access archive for the deposit and dissemination of scientific research documents, whether they are published or not. The documents may come from teaching and research institutions in France or abroad, or from public or private research centers.
L'archive ouverte pluridisciplinaire HAL, est destinée au dépôt et à la diffusion de documents scientifiques de niveau recherche, publiés ou non, émanant des établissements d'enseignement et de recherche français ou étrangers, des laboratoires publics ou privés. 


\title{
Thermomechanical processing and mechanical characteristics of particle-strengthened iron aluminide-based alloys
}

\author{
E. BATAWI, J. PHILLIPS*, J.A. PETERS and G. EGGELER ${ }^{*}$
}

Sulzer-Innotec, Division 1511, Materials and Surface Engineering, 8404 Winterthur, Switzerland

* Swiss Institute of Technology, Mechanical Metallurgy, Dept. Materials Science, 1015 Lausanne, Switzerland

\begin{abstract}
By the introduction of a fine dispersion of stable particles, a new family of chromium-containing iron aluminide-based alloys, has been developed. These alloys exhibited modified recrystallisation kinetics, creep and tensile strengths and welding characteristics. The existence of a second phase dispersion reduced the tendency for localised deformation. Uniform deformation was promoted and ductility improved. Dispersoid additions improved microstructural stability and the recrystallisation rate was retarded by more than a factor of two. The room temperature tensile ductility as well as the tensile strength of the particle-modified alloy were increased. Furthermore, the onset of micro void coalescence occurred at lower temperatures. At $700^{\circ} \mathrm{C}$ both alloys exhibited similar strain rate sensitivities. Charpy impact toughness tests showed that the ductile to brittle transition temperature for the thermomechanically treated alloys was approximately $250^{\circ} \mathrm{C}$ and about $50^{\circ} \mathrm{C}$ higher for the particle-containing alloy. This apparent decrease in impact toughness was attributed to large inclusions observed in the cast microstructure.
\end{abstract}

INTRODUCTION

The ever increasing need to avoid large concentrations of strategic elements as well as to achieve high temperature strength and excellent environmental resistance, have revived the interest in iron aluminidebased alloys as potential cost effective replacements for some high strength ferritic stainless steels. However, their use as engineering materials has been hindered by their low room temperature ductility, poor weldability and moderate creep strength. By means of grain structure control, alloying additions and thermomechanical processing, recent alloy development efforts have resulted in significant improvements in the room temperature ductility of $\mathrm{Fe}_{3} \mathrm{Al}$-based compositions $[1,2]$. Appropriate alloying, for example, the addition of chromium, has modified the kinetics of oxide formation as well as the dislocation dynamics and resulted in ductilities close to, or above $10 \%$ [3]. The addition of a stable second phase dispersion may serve many purposes, including: refinement of the cast microstructure and improvement in chemical homogeneity; increasing tensile strength; reducing grain size and improving the room temperature ductility; amelioration of the creep rupture life; modification of the dislocation dynamics; retardation of recrystallisation kinetics; and finally, provide better microstructural stability. Grain refinement by the addition of stable particleforming elements, such as titanium and boron, resulting in $\mathrm{TiB}_{2}$ dispersions, has been found to enhance the room temperature ductility of iron aluminide-based alloys. However, these particle-forming additions were found to segregate at grain and solidification cell boundaries during welding, thus promoting the formation of hot-cracks and reducing the alloy's weldability [4]. In an attempt to overcome this problem and promote overall microstructural stability, the rationale employed in this work encompasses the selection of second phase dispersoids which exhibit little or no partitioning tendency. This paper presents the results and compares the effect of a fine dispersion of stable particles on the thermomechanical processing, recrystallisation kinetics and mechanical characteristics of a chromium-containing iron aluminide alloy.

\section{EXPERIMENTAL METHODS}

Two experimental alloys were vacuum induction melted in alumina crucibles and cast into boron nitride coated graphite moulds. The starting stock was composed of commercial purity material that was slowly degassed in vacuum (10-4 mbar) before melting. Each heat consisted of approximately $35 \mathrm{~kg}$. The first casting was of a non-modified ("particle-free") alloy, while the second heat consisted of a particle-containing equivalent. The alloys studied had a base composition of $28 \mathrm{at} . \% \mathrm{Al}, 5 \mathrm{at} . \% \mathrm{Cr}, 0.5 \mathrm{at} \% \mathrm{Nb}$. Appropriate additions of other minor alloying elements resulted in 2-5 volume percent of dispersoids. Crack-free ingots approximately $55 \times 60 \times 300 \mathrm{~mm}$ were cast without any major difficulties. Small blocks, $55 \times 60 \times 60 \mathrm{~mm}$ in size, were then heated to $1000^{\circ} \mathrm{C}$ and uniaxially pressed to break up the cast microstructure. Hot and warm rolling was then performed on the thermally upset cakes. For each of the modified and unmodified alloys, thermomechanical processing sequences in the temperature range $1000-700^{\circ} \mathrm{C}$ were carried out, table 1 . The 
strain rates during rolling were controlled at $2 \mathrm{~s}^{-1}$ for the initial passes and gradually increased to a maximum of $6 \mathrm{~s}^{-1}$ when the plate thickness reached $5-10 \mathrm{~mm}$. After rolling, the hot plates were quenched in oil. The recrystallisation kinetics were evaluated after isothermal heat treatment at 600 and $700^{\circ} \mathrm{C}$ using optical and scanning electron microscopy of electrolytically polished samples. Tensile testing was performed on plates rolled at $800^{\circ} \mathrm{C}$ and recrystallised at $700^{\circ} \mathrm{C}$. In these samples the grain size of the unmodified and modified alloys was 75 and $10 \mu \mathrm{m}$, respectively. Flat tensile samples, $1.5 \mathrm{~mm}$ thick, were prepared by spark machining. The surface oxide scale, present as a result of thermomechanical processing was not removed. The crosshead speed was adjusted such that the net deformation rate was fixed at $3 \times 10^{-3} \mathrm{~s}^{-1}$. Testing was carried out under standard laboratory conditions, without specific control of the relative humidity. The strain rate sensitivity at $700^{\circ} \mathrm{C}$ for both alloys was evaluated by means of step tests. Sub-size Charpy impact toughness tests (DIN 50119 ) at various temperatures were also performed on samples spark machined from plates cross-rolled at $800^{\circ} \mathrm{C}$, reduced $97 \%$ in thickness and recrystallised at $700^{\circ} \mathrm{C}$.

Table 1 Rolling sequences evaluated for the thermomechanically processed plates

Sequence Process

$\begin{array}{ll}\mathrm{R} & \text { Hot roll } 1000^{\circ} \mathrm{C}, 90 \% \text {, oil quench } \\ \mathrm{S} & \text { Hot roll } 900^{\circ} \mathrm{C}, 90 \% \text {, oil quench } \\ \mathrm{T} & \text { Hot roll } 1000^{\circ} \mathrm{C}, 72 \% \text {, oil quench, warm roll } 800^{\circ} \mathrm{C}, 50 \% \text {, oil quench } \\ \mathrm{U} & \text { Hot roll } 1000^{\circ} \mathrm{C}, 72 \% \text {, oil quench, warm roll } 700^{\circ} \mathrm{C}, 50 \% \text {, oil quench }\end{array}$

\section{RESULTS AND DISCUSSION}

Figure 1 represents the optical micrographs of plates rolled according to sequences $\mathrm{R}$ and $\mathrm{U}$. At $1000^{\circ} \mathrm{C}$ both alloys consisted of a fine recrystallised microstructure, suggesting that dynamic recrystallisation had taken place. The presence of a fine dispersion had nevertheless reduced the grain size in the particle-containing alloy, figure 1a. After rolling in the range $700-900^{\circ} \mathrm{C}$, elongated grains were present in both alloys, with

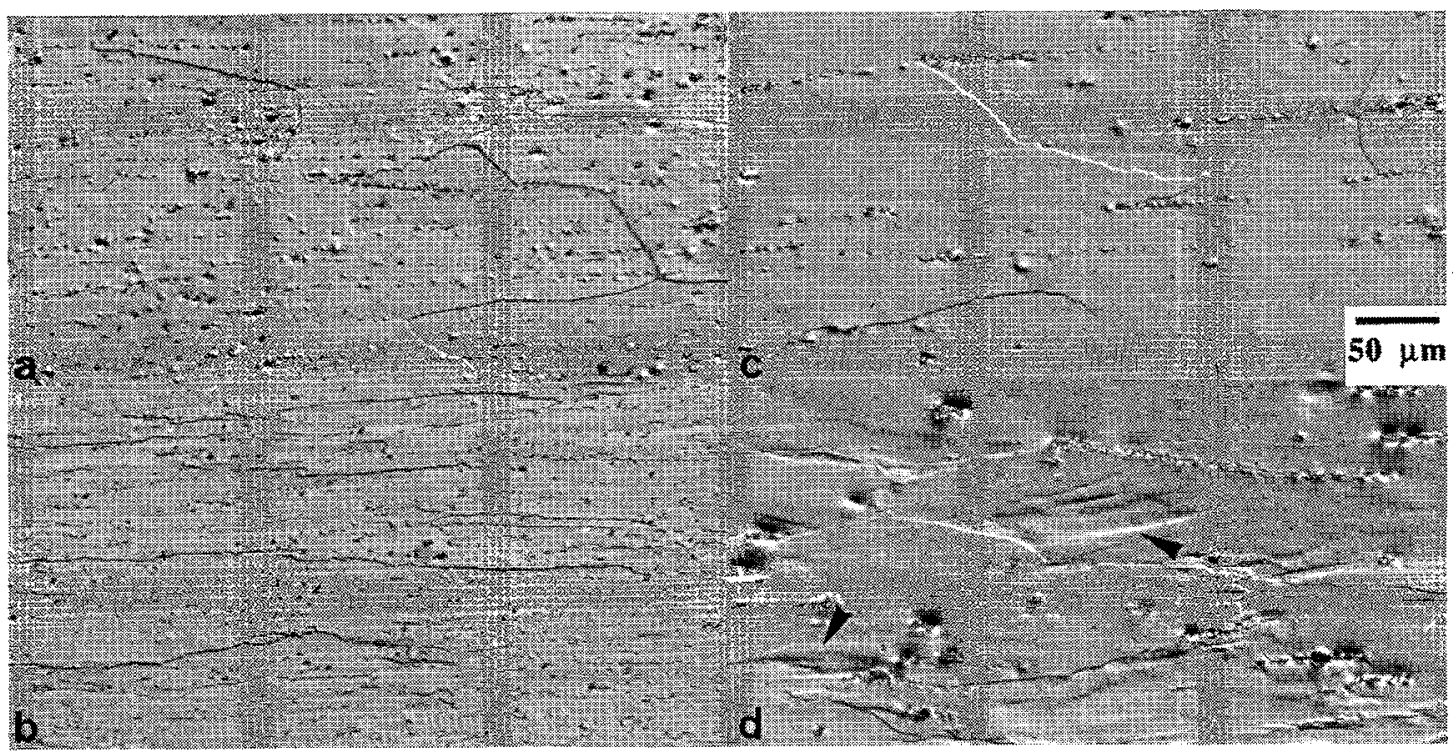

Figure 1 Grain structure of thermomechanically processed samples according to sequence $R$ and $U$. Figures a and $b$ represent the modified alloy and $c$ and $d$ the un-modified.

no visible signs of dynamic recrystallisation, suggesting that the limit for dynamic recrystallisation was between 900 and $1000^{\circ} \mathrm{C}$ for both alloys. In the case of the dispersion-free alloy, indications of heavily localised deformation were found (arrows in figure 1d). The large particles observed in this structure were niobium-rich and did not seem to influence the deformation in any significant manner. Their presence was not a consequence of additional alloying, since they were also present in the modified alloy. However, in the case of the particle-containing alloy, similar signs of heavily localised deformation could not be detected, suggesting that the second phase dispersion had reduced the tendency for localised deformation, figure $1 \mathrm{~b}$.

Figure 2 represents a histogram of the time to achieve $50 \%$ recrystallisation as a function of alloy and thermomechanical treatment. If it is assumed that the residual dislocation density increases in the order of thermomechanical sequence $R, S, T$ and $U$, due to reduced thermal activation, there appears to be an increase in the recrystallisation velocity with the residual dislocation density. The presence of a fine dispersion of second phase particles, at $600^{\circ} \mathrm{C}$, seemed to have reduced the recrystallisation rate by approximately a factor of two. However, this effect was lost at $700^{\circ} \mathrm{C}$, where the times were similar for the two alloys.

Figure 3 shows the Charpy impact toughness as a function of temperature. The ductile to brittle transition was approximately $250^{\circ} \mathrm{C}$ for the non-modified alloy. However, it was found to be some $50^{\circ} \mathrm{C}$ higher for the 
particle-containing counterpart. The upper and lower shelves were similar. Detailed examination of the fracture surfaces showed that below the DBTT, mixed fracture occurred, characterised by transgranular and intergranular cleavage.

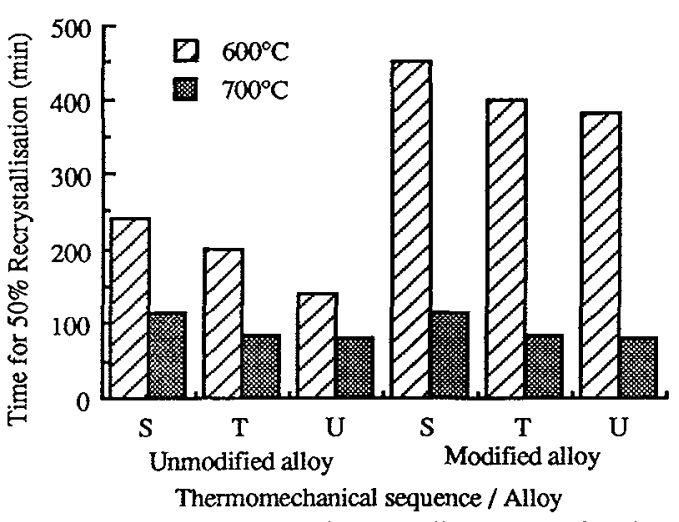

Figure 2 Time to achieve $50 \%$ recrystallisation as a function of temperature and thermomechanical sequence.

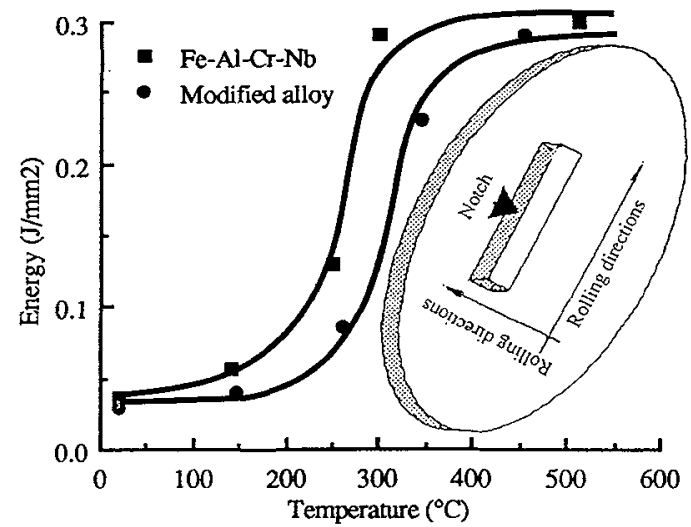

Figure 3 Charpy impact toughness (DIN 50119 ) as a function of temperature for both alloys.

Figure $4 \mathrm{a}, 4 \mathrm{~b}$ and $4 \mathrm{c}$ represent the average values of yield stress, tensile strength and elongation to failure, respectively, as a function of temperature. The particle-strengthened alloy showed superior yield stress and ductility at all temperatures. Below $400^{\circ} \mathrm{C}$ it was characterised with a higher work hardening rate, resulting it tensile strengths higher than those of the unmodified alloy. However, above this temperature the work hardening rate of the modified alloy dropped and in consequence, the tensile strengths for both materials were similar. These observations would suggest a modification in the interaction mechanisms between dislocations and particles in the particle-containing alloy. At present, the reason for this change in dislocation-particle interaction is unclear.

It is now generally accepted that the ambient temperature brittleness of iron aluminide-based alloys may be attributed to their poor cleavage strength, due to hydrogen embrittlement [5]. Although the absolute ductility values for both alloys were not significantly high, the presence of a fine dispersion has resulted in an increase in ductility of approximately $50 \%$. The low absolute values could be explained by the fact that both alloys were tested in the recrystallised state, found to be less favourable to ambient temperature ductility [6], as well as by the possibly high levels of humidity during testing. However, the improved ductility of the particle-containing alloy may be attributed to its smaller grain size, conferred by grain boundary pinning.

The fine grain structure and relatively high elongation at $700^{\circ} \mathrm{C}$, would suggest that the particle-containing alloys may be amenable to superplastic forming. Figure $4 \mathrm{~d}$ shows the variation of stress as a function of strain rate. The strain rate sensitivity, $\mathrm{m}$, calculated as $\Delta \log \sigma / \Delta \log \varepsilon$, was found to be 0.18 and 0.19 for the particle-containing and particle-free alloys, respectively. These values are in agreement with those measured by other researchers [7] and are lower than the accepted limit for superplasticity, suggesting that superplastic behaviour is unlikely for these alloys at these temperatures. Figures $4 \mathrm{e}-4 \mathrm{~h}$ represent scanning electron micrographs of the fracture surfaces of the tensile samples tested at room temperature and $200^{\circ} \mathrm{C}$. Both alloys showed a mixed trans- and intergranular cleavage-like failure mode at room temperature. However, the river patterns observed in the particle-containing alloy were finer, suggesting that for this alloy more pronounced crack deviation had occurred. Furthermore, at $200^{\circ} \mathrm{C}$ the modified alloy showed some ductile transgranular rupture (arrows in figure $4 \mathrm{~g}$ ). At this temperature the unmodified alloy still failed by mixed cleavage. These observations seem to be in disagreement with the Charpy impact values where the particlecontaining alloy was characterised with lower macroscopic impact toughness than its particle-free counterpart. This discrepancy may be explained by the existence of some large inclusions detected in the microstructure of the modified alloy. These inclusions acted as crack initiators during impact and reduced the impact toughness of the material. Better control of casting parameters and a remelting step should eliminate these inclusions.

\section{CONCLUSIONS}

The recrystallisation kinetics, tensile properties, impact toughness behaviour and superplastic formability of a particle strengthened iron aluminide was compared to a particle-free alloy of the same base composition. The addition of a second phase dispersion encouraged uniform deformation and improved the ductility and yield stress at all temperatures. For both alloys, dynamic recrystallisation occurred at $1000^{\circ} \mathrm{C}$. The dynamically recrystallised structure for the modified alloy was finer probably due to improved microstructural stability arising from grain boundary pinning. At $600^{\circ} \mathrm{C}$ the time for $50 \%$ recrystallisation was doubled. Strain rate sensitivity tests showed that even though a fine recrystallised structure was obtained after thermomechanical processing, superplastic forming would be unlikely for both alloys. The presence of dispersoids did not affect the values of strain rate sensitivity at $700^{\circ} \mathrm{C}$. The low DBTT value observed for the particle-containing alloy was attributed to the presence of large inclusions in the cast microstructure. However, for this alloy the onset for micro-void coalescence occurred at lower temperatures, demonstrating that the presence of a fine dispersion of stable particles improved the deformation behaviour. 

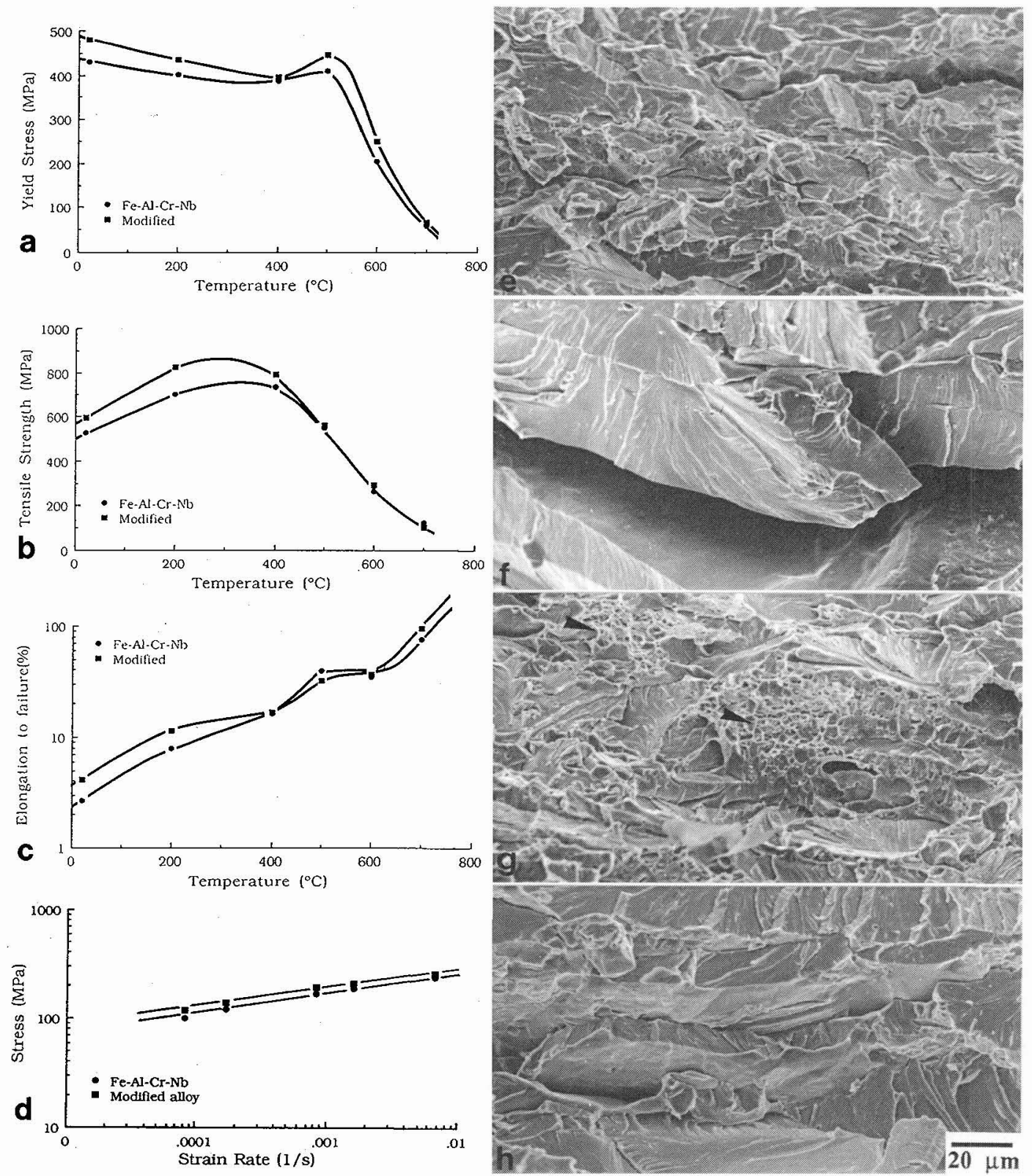

Figure 4 a) yield stress, b) tensile strength and c) elongation to failure, as a function of temperature. d) strain rate as a function of stress. $e), f), g$ ) and $h$ ) are scanning electron micrographs of the rupture surface of the modified $(e \& g)$ and unmodified $(f \& h)$ alloys tested at room temperature and $200^{\circ} \mathrm{C}$, respectively.

[1] J. R. Weir and R. Daghir: ORNL Materials Highlights, ORNL/M-1287/R1, ORNL, Oak Ridge, TN, USA, Dec. 1992

[2] P.G. Sanders, V.K. Sikka, C.R. Howell and R.H. Baldwin, Scripta Met. Metall., 25, 1991, p.2365

[3] C.G. McKamey, J.A. Horton and C.T. Liu, Scripta Metall., 22, 1988, p.1697

[4] S.A. David, J.A. Horton, C.G. McKamey, T. Zacharia and R.W. Reed, Welding Research Sup., Sept., 1989, p. 372

[5] C.T. Liu, E.H. Lee and C.G. McKamey, Scripta Metall., 23, 1989, p.875

[6] C.G. McKamey and D.H. Pierce, Scripta Metall. Mater., 28, 1993, p.1173

[7] J.R. Knibloe, R.N. Wright, V.K. Sikka, R.H. Baldwin and C.R. Howell, Mat. Sci. Eng., A153, 1992, p.382 